\title{
Benevolence: lived experiences of staff nurses
}

\author{
John Christian V.Villanueva \\ Department of Education - Schools Division of Nueva Ecija, Cabiao National Senior High School, Dr. Gloria D. Lacson Foundation Colleges, The Good \\ Samaritan Colleges, Philippines
}

\author{
Correspondence: John Christian V.Villanueva, Department of Education - Schools Division of Nueva Ecija, Philippines. \\ Email villanuevajohnchristian@ymail.com
}

Received: October 10,2018 | Published: November 12, 2018

Copyright@ 2018 Villanueva. This is an open access article distributed under the terms of the Creative Commons Attribution License, which permits unrestricted use, distribution, and reproduction in any medium, provided the original author and source are credited.

\begin{abstract}
Caring, the act of giving care, is seen through history as an essential part of being human and humanity. The Filipino society is generally known to be a caring community, which includes sacrificing their own resources for the benefit of their fellow citizens. Caring is embedded within the culture which is why Filipinos find it easy to care for someone with whom they are unrelated by affinity or nationality; therefore, Filipinos are highly in demand globally in terms of health care services, particularly nursing. Benevolence (Pagkamapagkawanggawa) is a bioethical principle that is innate within the Filipino culture. Heuristic phenomenological method was adopted by the researcher to explain thoroughly the experiences of the researcher and participants and to develop a comprehensive understanding of their realities. Following Moustakas' heuristic process, a matrix of categories and themes were developed. There were six themes extracted from the data gathered:
\end{abstract}

\section{Introduction}

Caring, the act of giving care, is seen through history as an essential part of humanity and being human. According to Covington ${ }^{1}$, caring presence is defined as an interpersonal, intersubjective human experience of connection within a nurse-client relationship that makes it safe for sharing oneself with another. Additionally, Pask $^{2}$ noted that as clients benefit from caring practices, the nurses involved in these situations experience caring through knowing that they have made a difference in their client's lives. As nurses feel free to concentrate their attention upon the other, they can make positive difference to clients. The ability to give focused attention to clients means leaving the egocentric self behind.

The Filipino society is generally known to be a caring community, which includes sacrificing their own resources for the benefit of their fellow citizens. Caring is embedded within the culture which is why Filipinos find it easy to care for someone with whom they are unrelated by affinity or nationality, therefore Filipinos are highly in demand globally in terms of health care services, particularly nursing.

Benevolence (Pagkamapagkawanggawa) is a bioethical principle that is indeed innate within the Filipino culture. According to Kuan ${ }^{3}$, benevolence refers to the character trait or virtue of being inclined to do good or act for the benefit of others. It makes the nursing practice in the Philippines different from other countries because Filipino nurses also dedicate themselves for the betterment of others.

Moreover, Martinez ${ }^{4}$ noted that it is not the responsibility of a nurse to go beyond what the profession dictates, but there is an unexplained desire to share the burden and suffering of their fellowman and treat it as their own. During these times, nurses unconsciously feel that
"Influential Body", "Nursing Ideals", "Nurses as Acting Body", "Consideration and Limitation", "The Joy of Helping" and "Transformation of Nurses". The implication of this study to the nursing education and research is that nursing students will be aware of the possible reasons, purposes and effects of benevolence on the life of the staff nurses. A training plan was developed and organized for the staff nurses that has goal in transforming them, through benevolence. This seeks to provide each staff nurses to enhance benevolent spirit, experience the unconditional joy and love for others. This will also give a certain boost with their feelings and develop a much better viewpoint with regards to benevolence to be infused with their daily nursing care routine. Another output is a poem that was born resulting from the continual reflection of the insight of the phenomenon.

Keywords: nursing experiences, phenomenological study, heuristic method

those whom they care for are not merely individual, but fellow human beings like themselves. He added that caring is not resource bound but rather resource sensitive, that resources are not limited but limitless if one has the will to create them. Caring, in this context, is humanity's way of sharing the cosmic abundance.

In each one of us, there is that inner goodness that pushes us for heroic acts of self-sacrifice to benefit others.

The researcher chose this topic because it is somehow related to the researcher's heart for having a personal and passionate experience on the phenomenon.

The purpose of this study was to explore the common lived experiences of staff nurses on benevolence in their work setting.

This research will enable nursing administrators to cultivate the Filipino culture of benevolent acts. Also, this may serve as a consideration in developing and updating hospital policies and protocols in delivering efficient and quality health care services. The study will also remind nurses to incorporate benevolent attitude in the practice of their calling. With this sense, they will be an active agent of nation building in transforming health care services in the country. Lastly, this study can enrich a patient's appreciation and satisfaction in the delivery of healthcare services which upholds benevolent spirit. This appreciation will also enable nurses to build on their innate resourcefulness and cultural strength.

\section{Objective}

This study explored the experiences of staff nurses on benevolence and sought to answer these questions: 
1. What is the profile of the respondents in terms of:

1.1 Age;

1.2 Gender;

1.3 Educational Attainment;

1.4 Civil Status;

1.5 Religion; and

1.6 Length of Service?

2. How does the phenomenon of lived experiences on benevolence exist in the workplace of the respondents?

3. What meanings and insights may be concluded from the respondents' experiences?

4. Based on the findings, what output may be proposed by the researcher?

\section{Materials and methods}

Phenomenological method, as part of qualitative research, was used in this study because in using this method the researcher tries to figure out a certain phenomenon through interviewing selected respondents, who are in our case staff nurses. The discipline of phenomenology may be defined initially as the study of structures of experience, or consciousness.

Based on Moustakas ${ }^{5}$ (as cited in Creswell ${ }^{6}$ ) heuristic phenomenological method was adopted by the researcher to explain thoroughly the experiences of the researcher and participants and to develop a comprehensive understanding of their realities. This method seeks to discover the heart and depths of a person's experience portraying events and relationships, thoughts and feelings, values and beliefs - recreating the lived experience from the perspective of the person who experiences it. The researcher used the method to obtain more knowledge about a certain phenomenon and its meaning; the researcher discovers a new way to see and understand the phenomenon of interest. A deepening awareness of the human experience's meaning does not only extend scientific knowledge, but also illuminates the researcher itself.

All the respondents work as bedside nurses in selected government hospitals in Cabanatuan City, rendering direct patient care and have experience doing benevolent acts. The interviews were transcribed verbatim by the researcher and the accuracy was checked. The data was gathered and analyzed using Moustakas' heuristic process.

\section{Initial Engagement phase}

This begins with an autobiographic self-search and the researcher's deeply demanding, disciplined commitment to the phenomenon. The research question grew out of a personal and passionate connection with the phenomenon of interest. The researcher was engaged in self-awareness and self-dialogues to build originality and perceive wholeness, adding depth to the discovery process. The researcher recorded thoughts and feelings emerging through tacit knowing, intuition, and engaging in the phenomenon through reading, observing, and living the research experience in a personal journey. As the research question depended clearly by the researcher's desire to understand the human experience more deeply, methods and procedures were developed which guided the collection of data to answer the question.
The researcher carefully designed the study around the philosophy and ontology of the heuristic method. The researcher planned strategies for the selection of respondents, protection of respondents' rights, and a data analysis process appropriate to the method.

Descriptions of the phenomenon's lived experience were generally gathered through extended interviews, in which the researcher encouraged a free flow of ideas, feelings, and images to unfold naturally. The researcher created a climate of openness and trust, often using self-disclosure to inspire a more comprehensive description from the respondent.

To supplement the interview data, the heuristic researcher also collected personal documents such as diaries, poetry, artwork, music, and other meaningful expressions of the experience from the participants. All data were analyzed to discover the true meaning of the experience for the respondents.

\section{Immersion phase}

This begins once the interviews were conducted and the researcher became completely involved or immersed in the data. The researcher gained a gradual sense of meaning, being completely open to discovering meanings in everyday observations with other people, situations, nature, music, art, and publications such as autobiographies, biographies, fiction, and poetry. Fundamental insight was achieved through the process of indwelling or personal reflection. The researcher dwelled in the respondent's unique experience.

\section{Incubation phase}

Following the extended period of intense focus, the researcher relaxed and detached somewhat from the question, in an effort to gain new visions of understanding through the inner tacit dimension. Flashes of insight and creative perspectives sparked through rest and diversion.

\section{Illumination phase}

At some unspecified point, a clear sense of direction presented itself and themes, qualities, and patterns of the phenomenon emerged. The researcher co-created a valid depiction of the experience being investigated, engaged in meaning of the experience through a personal and a disciplinary lens. Misunderstood realities were exposed and the truth of the experience was revealed. According to Moustakas ${ }^{5}$ (cited in Casterline ${ }^{7}$ ), this phase heralds nuances in meaning and the "discovery of something that has been present for some time yet beyond immediate awareness."

\section{Explication phase}

The researcher used focusing, indwelling, self-searching, and selfdisclosure to thoroughly examine various layers of meaning within the data. The researcher created an inward space to acknowledge textures and themes derived from the conversations and dialogues with others. A comprehensive depiction of the dominant themes or core essences for each participant's experience was developed. Once individual depictions were identified, a composite description of the experience was constructed, creating an exemplary portrait which illustrated the core meanings of the phenomenon as experienced by the respondents yet characterizing the group as a whole.

\section{Creative Synthesis phase}

Emerging from the respondents' experiences and the researcher's personal knowledge of the phenomenon, the creative synthesis took shape as an artistic representation of the findings. The creative 
synthesis was an art form created uniquely by the researcher or one discovered by the researcher in the form of a story, poem, drawing, sculpture, music, textiles, or other creative form, which supported the researcher's knowledge and passion of the experience.

\section{Results}

Following Moustakas' heuristic process, a matrix of categories and themes were developed from the data. Irrelevant comments were omitted; meanings were categorized, and themes were allowed to surface. There were six themes extracted from the data gathered: "Influential Body", "Nursing Ideals", "Nurses as Acting Body", "Consideration and Limitation", "The Joy of Helping" and "Transformation of Nurses" (Table 1). Within the first theme, three following categories were identified: church influence, school influence and familial influence; four categories arose in the second theme: proper assessment, patient care, nursing role and commitment. Five categories were identified on the third theme: commiseration, resourcefulness, generosity, altruism and compassion; and two categories under the fourth theme fall under the following: marked consideration for others and setting limits towards independency. Three categories were identified on the fifth theme: happiness on helping, fulfillment and enjoyment of work; and one category under the sixth theme: transformation of nurses. These were explored continuously in this chapter.

Table I Themes and categories identified by the gathered data

\begin{tabular}{ll}
\hline Theme & Category \\
\hline Influential body & Church influence \\
School influence \\
Familial influence \\
Proper assessment \\
Patient care \\
Nursing ideals & Nursing role \\
& Commitment \\
& Commiseration \\
& Resourcefulness \\
Nurses as acting body & Generosity \\
& Altruism \\
& Compassion \\
Consideration and limitation & Marked consideration for others \\
& Setting limits towards independency \\
The joy of helping & Happiness on helping \\
\hline & Fulfillment \\
\hline Ensformation of nurses & Transformation of nurses \\
\hline
\end{tabular}

\section{Theme I. Influential body}

Influence is the capacity to have an effect on the character, development and behavior of someone. Nurses are often influenced by the environment. They are like sponges that can absorb all liquids placed near them.
In the first theme, three categories were identified: church influence, school influence and familial influence.

\section{Theme 2. Nursing ideals}

Nursing is a profession within the health care sector focused on the care of individuals, families and communities so they may attain, maintain or recover optimal health and quality of life.

The aim of the nursing community worldwide is for its professionals to ensure quality care for all, while maintaining their credentials, code of ethics, standards and competencies and continuing their education.

Nursing practice is the actual provision of nursing care. In providing care, nurses implement the nursing care plan using the nursing process. In general terms, the nursing process is the method used to assess and diagnose needs, plan outcomes and interventions, implement interventions and evaluate the outcomes of the care provided.

In this theme, four categories were identified: proper assessment, patient care, nursing role and commitment.

\section{Theme 3. Nursing as acting body}

Nurses care for individuals of all ages and cultural backgrounds who are healthy and ill in a holistic manner based on the individual's physical, emotional, psychological, intellectual, social and spiritual needs. In this theme, the participants served as the acting body for benevolence in their nursing care.

In the third theme, five categories were identified: commiseration, resourcefulness, generosity, altruism and compassion.

\section{Theme 4. Consideration and limitation}

Nurses do consider the socioeconomic status as they render nursing care to their patients. They often perform benevolent actions to those who are really in-need and unable to pay for their medical expenses. As they become considerate, nurses also limit their benevolent actions to patients towards independence. Nurses limit to provide the maintenance of legal, ethical and professional standards.

In this theme, two categories were identified: marked consideration for others and setting limits towards independence.

\section{Theme 5.The joy of helping}

According to Gunderman ${ }^{8}$, people need to give of themselves, those who help them discover the joy of giving. Nurses experienced the joy of helping when they perform benevolent actions. As King ${ }^{9}$ said, it is a privilege to extend helping hands to people regardless of whom, what or where they are; love and mercy transcends in races, nationalities and geographical distance. Givers owe hearty thanks to their receivers, because it is their unfortunate condition that makes it possible for them to know the joy of giving.

In the fifth theme, three categories were identified: happiness on helping, fulfillment and enjoyment of work.

\section{Theme 6. Cracking the eggshell: transformation of staff nurses}

Becoming a nurse is a job that one can feel good about. They will make positive contribution to society. They are sharing their care to fellow human beings. They may have the opportunity to save someone's life. By uplifting patients and giving them hope in their time of need, nursing will affect one's life. Nurses often feel as though their life has purpose because they are doing something that matters. 
The researcher had viewed the transformation of staff nurses, cracking the eggshell, as their lived experiences on benevolence. Eggshell symbolizes the essence of nursing as it protects the life inside it. As time passed by, cracks will appear, and the organism will be hatched. This is to show to the world the perfect image of the nursing profession. Nurses will spread their wings as a protective shield for their patients while also rendering their essential needs. Most especially having a heart that offers unconditional love and cares without any hesitation and expecting of returns.

\section{Discussion}

This study provided answers to the following questions:

\section{What is the profile of the respondents?}

Most of the respondents are female, all are single in civil status and the majority of them are Roman Catholic. They belonged to age bracket of 22-25 years old and were BSN graduates. The range of their length of service was 1-4 years with the mean length of service of 2.4 years.

How does the phenomenon of lived experiences on benevolence exist in the workplace of the respondents?

The staff nurses verbalized that they were influenced by the church, school and their own family in doing benevolent actions to their patients. The knowledge imparted to them displays the nursing profession as a whole. Nurses carry out the tasks with marked considerations and limitation on helping patients towards selfreliance. In line with this, they will appreciate the joy of giving and experience the transformation from a simple image of nursing to its perfection.

\section{What meanings and insights may be concluded from their experiences?}

There were six themes extracted from the data gathered: "Influential Body", "Nursing Ideals", "Nurses as Acting Body", "Consideration and Limitation", "The Joy of Helping" and "Transformation of Nurses". Within the first theme, three following categories were identified: church influence, school influence and familial influence; four categories arose in the second theme: proper assessment, patient care, nursing role and commitment. Five categories were identified on the third theme: commiseration, resourcefulness, generosity, altruism and compassion; and two categories under the fourth theme fall under the following: marked consideration for others and setting limits towards independency. Three categories were identified on the fifth theme: happiness on helping, fulfillment and enjoyment of work; and one category under the sixth theme: transformation of nurses. A conceptual model was made to further enhance the understanding of the lived experiences of staff nurses.

\section{Implications to the Nursing Practice}

This study was conducted using Moustakas' heuristic process and the researcher argues that phenomenological research approaches are most fitted for inquiry into people's lived experiences. By listening to the participants in this study and reflecting on their experiences, the researcher gained a new perspective of nurses' situations who are involved in doing benevolent actions in the nursing care of their patients. The implication of the study to the nursing practice is that staff nurses will cultivate the Filipino culture of benevolence. They will serve as an active agent for nation building in transforming health care services in the country. This will orient them about the marked consideration, limitation on helping patients towards self-reliance, appreciation of joy-giving and experiences of the self-transformation.

\section{Implications to the Nursing Research and Education}

This study gave information about the participants' feelings, emphasizing about the importance of benevolence in the nursing profession. The implication of this study to the nursing education and research is that nursing students will be aware of the possible reasons, purposes and effects of benevolence on the life of the staff nurses. The researcher understands this study to encourage other researchers for further research and incorporated them to nursing education. The study will contribute to the phenomenological aspects of lived experiences of staff nurses on benevolence, understanding more on their feelings and knowledge contributing to the education of the present nursing program. The researcher has gained information about different perspectives of staff nurses doing benevolent actions in their nursing care and able to understand their experiences by carefully analyzing and interpreting it.

\section{Based on the findings, what output is proposed by the researcher?}

\section{The Training Plan}

A training plan is developed and organized for the staff nurses that has goal in transforming them, through benevolence. It will nurture their attitudes and professional growth and development. This may help them to become the stewards of change and good deeds to the people, community and the entire nation.

This training plan seeks to provide each staff nurses to enhance benevolent spirit, experience the unconditional joy and love for others. This will give a certain boost with their feelings and develop a much better viewpoint with regards to benevolence to be infused with their daily nursing care routine.

It includes evaluation of the perception of benevolence, before and after the training, discussion of the main topic from a resource speaker, planning and conducting of a fund-raising activity and immersion to charity wards of a government hospital and deprived communities.

\section{Artistic Expression}

Another output is the following poem that was born resulting from the continual reflection of the insight of the phenomenon. It reflects the appreciation of the lived experiences of staff nurses on benevolence and was agreed upon by the participants upon seeing it. This poem thus reached a resonance between the researcher's appreciation and participants' experience.

\section{Cracking the Eggshell}

Angel that was brought by heaven to the land Always ready to help Because these were their vowed words To care for God and His country.
Anghel na dulog ng langit sa lupa Handang tumulong at magkawang-gawa Sapagkat ito'y mga sumpang salita Sa Diyos at bayan laging kumalinga. 


\author{
Pagtulong na mula sa kanilang awa \\ Gagawa ng paraan para sa kapwa \\ 'Pagkat mga anghel sadyang maalaga \\ Kahit barya sa bulsa'y maubos, mawala. \\ Ang gawaing ito'y nagbibigay saya \\ Kapag tinulunga'y ngumiti sa kanila \\ Lubos na ligaya ang nadarama \\ Ang dedikasyon sa trabaho'y dagdag pa. \\ Tulad ng balat ng itlog na may lamat \\ Binabago ang pagkatao't minumulat \\ Sa totoong sitwasyon na kulang at salat \\ Diyos na ang bahalang magsukli sa lahat.
}

\section{Conclusion}

Based on the findings, the following conclusions are drawn.

1. Majority of the staff nurses were in the young adulthood stage, female, and single. Most of them graduate in college education and Roman Catholic.

2. Benevolence of staff nurses are commonly influenced by the following factors: church, school and family, in doing benevolence on nursing care for their patients.

3. Proper assessment, implementation of patient care, accomplishing the nursing role and commitment to the nursing profession are part of the nursing ideals that aims to achieve quality nursing care.

4. Staff nurses' commiseration on poor and indigent patients results to benevolence.

5. Resourcefulness is an innate characteristic of Filipino nurses as they used to work in the setting that scarcity of supplies and equipments is a great issue.

6. There is a marked consideration in nursing care, placing those who are in-need, indigent and poor patients as the beneficiaries of benevolent actions of staff nurses. Additionally, limitation of helping to those who become dependent and abusive behavior to lead them to self-reliance.

7. Appreciation of the patients for the benevolent actions produces the happiness of the staff nurses, and they realize what the joy of giving is.

8. Benevolence transforms staff nurses, as they become better and effective nurses, who are committed for the work and willing to extend help to the people.

\section{Recommendations}

Based on the findings presented and conclusions drawn, the following recommendations are hereby given.

1. Nursing administrators must consider the aspect of benevolence in the nursing care of their subordinates, to achieve efficient and

\author{
Helping that comes from their mercy \\ They will do everything for others \\ Because angels are really caring \\ Even coins in the pocket become totally \\ consumed. \\ These brought joy \\ When the people they helped, smile on them \\ They feel joyful \\ And dedicated to their work. \\ Like the cracks in the eggshell \\ It changed and enlightened someone \\ In a real and scarce situation \\ They let God pay, in behalf of their neighbors.
}

quality health care delivery. This can also be imparted in the staff development program of their institution, through seminars and trainings, to uplift the attitude and behavior of their staff nurses.

2. Nursing educators must emphasize the value of benevolence to their nursing students, either in classroom or clinical setting. They should be the first one to understand the concept of benevolence, in order to appreciate its goodness and beauty.

3. Readers and other researchers can elicit and pursue more studies about lived experiences of staff nurses on benevolence utilizing other methodological approach to further validate the data that have been gathered in this study.

\section{References}

1. Covington H. Caring presence. Delineation of a concept for holistic nursing. J Holist Nurs Off J Am Holist Nurses Assoc. 2003;21(3):301-317. doi: $10.1177 / 0898010103254915$

2. Pask EJ. Moral Agency in Nursing: seeing value In the work and believing that i make a difference. Nurs Ethics. 2003;10(2):165-174. doi:10.1191/0969733003ne591oa

3. Kuan LG. Bioethics in Nursing. Ermita Manila: Educational Publishing House; 2006

4. Martinez CRKP. Hinabing Ugnayan: Nature of Caring Among Filipino Nurses Working with Children. 2013. https://sigma.nursingrepository. org/bitstream/handle/10755/623658/RCKM_Dissertation. pdf;jsessionid=DBD4F0CB484EEF4DBC5FF406B4FDD375? sequence $=6$. Accessed November 5, 2018.

5. Moustakas C. Phenomenological Research Methods. 2455 Teller Road, Thousand Oaks California 91320 United States of America: SAGE Publications, Inc.; 1994. doi:10.4135/9781412995658

6. Creswell JW. Qualitative Inquiry \& Research Design Choosing Among Five Approaches. Sage Publications. Thousand Oaks CA. 2007.

7. Casterline GL. Heuristic inquiry: Artistic science for nursing. South Online J Nurs Res. 2009;9(1):1-7.

8. Gunderman RB. We Make a Life by What We Give. Indiana University Press; 2009

9. King SB. Being Benevolence: The Social Ethics of Engaged Buddhism. Honolulu: University of Hawaii Press; 2005. 